\title{
Stress Analysis of Buried Gas Pipeline Traversing Sliding Mass
}

\author{
Liqiong Chen, Shijuan Wu, Hongfang Lu*, Kun Huang, Yitang Lv and Jiali Wu
}

\author{
School of Petroleum Engineering, Southwest Petroleum University, Chengdu, China
}

\begin{abstract}
Landslides are one of the primary dangers associated with gas pipelines. Pipeline spans can be divided into two categories: longitudinally traversing and laterally traversing. The load brought on by a landslide can cause pipeline failure, thus stress analysis of both ways of traversing is of great necessity. Through stress analysis, the junction of the conventional buried pipeline and the landslide has been confirmed as coming under the heaviest loads. Therefore, stress checks against accidental loads should be emphasized during the stress analysis of gas pipelines traversing sliding masses.
\end{abstract}

Keywords: Gas pipeline, landslide, lateral traverse, longitudinal traverse, pipeline crossing, slide mass, stress analysis.

\section{INTRODUCTION}

China has many different types of landscapes, and landslides are one of the major geological hazards. It is impossible to avoid laying pipelines in landslide areas, but at the same time, the damage caused by the process of laying pipelines can also be the cause of landslides in some regions. When traveling through landslide areas, gas pipelines are easily affected by sliding soil, which can lead to pipeline fractures due to stress and deformation. For examples, the Gas Pipeline Project (Line 2), Se-Ning-Lan Pipeline project, Shan-Jing (Line 2), Zhong-Wu Line, and the Lan-Cheng-Yu Pipeline Project were all built in regions of high landslide threats, which could lead to varying degrees of damage to the pipelines. Because of the potential danger, it is necessary to do stress analysis of the pipelines that cross landslide areas, after which stress distribution can be better understood, and according to the results, feasible engineering measures can be put in place to ensure safe operation [1,2]. Presently, stress analysis of pipelines is limited to static analysis. In 2011, Xiaonan carried out static analysis of a tunnel gas pipeline, including the installation, operation, and pigging conditions. The areas of his pipeline stress analysis were primarily in the mountainous areas and in the tunnel, while little research was conducted on geological disaster areas [3-11].

CAESAR II is software based on the theory of onedimensional beam finite element stress analysis, and is normally used for stress analysis in the research of longdistance pipelines. Because the length of a pipeline in the axial direction is far greater than its diameter, a pipeline is usually simplified to a one-dimensional beam element model, and the effects of cross-sectional changes are ignored. According to a map of the pipeline, a pipe model is set up. In practical engineering, seamless steel tubing is used

*Address correspondence to this author at the Southwest Petroleum University, Chengdu, China; Tel: +86-187-8299-2609;

Fax: +86-187-8299-2609; E-mail: swpuluhongfang@126.com and the line is treated as a whole. However, in the software simulation process, to ensure accurate results, the weight of the pipe sections are evenly distributed and concentrated at the pipe ends of the nodes. The stress analysis is implemented through the calculation of the nodes. Basically, the stress conditions of the nodes equal that of the pipes.

For the gas pipeline stress checks, GB50251 gas pipeline engineering design specifications were used in this study, while ASME B31.8 guidelines for gas transmission and distribution of pipeline systems are generally used. Although the two standards are different, the descriptions of stress checks are basically the same. CAESAR II software follows ASME B31.8 stress check guidelines.

\section{METHODS}

Stress analyses of gas pipelines running through landslide areas were conducted. Compared to pipelines in average geographical regions, this required the application of landslide load stresses on the pipes. Under normal circumstances, landslide loads can be broken down into two directions: horizontal and vertical. After entering the calculated load value into CAESAR II, and computing, the stress levels were checked against ASME B31.8 standards.

\subsection{Load Calculation of Pipeline Through Landslide Area}

There are two ways for pipeline to travel, laterally and longitudinally, and they are considered different in pipeline stress analysis. The direction of laterally traversing pipelines deform in a way that is perpendicular to the direction of the landslide, while the longitudinally traversing pipelines are subject to the axial frictional force of the soil.

Because of the relative positions of the landslide and the laterally traversing pipeline, the even load of the pipeline focuses on lateral and parallel directions. When calculating the even load in those two directions, refer to Formula (1) and (2) $[12,13]$ : 
$U_{\text {transverse }}=Q \times \cos \alpha$

$U_{\text {longitudinal }}=Q \times \sin \alpha$

where $Q$ is the landslide thrust and $\alpha$ is the landslide angle.

The moving direction of a longitudinal landslide is parallel to the buried pipelines. The even load the pipelines are subject to in a longitudinal slide focus on axial and parallel directions. Therefore, when calculating the even load in these two directions, take Formula (3) and (4) as reference:

$U_{\text {longitudinal }}=Q \times \sin \alpha$

$U_{\text {axial }}=Q \times \cos \alpha$

where $Q$ is the landslide thrust, $\alpha$ is the landslide angle.

The force situations of a laterally traversing and longitudinally traversing pipeline are shown in Figs. (1 and 2), respectively.

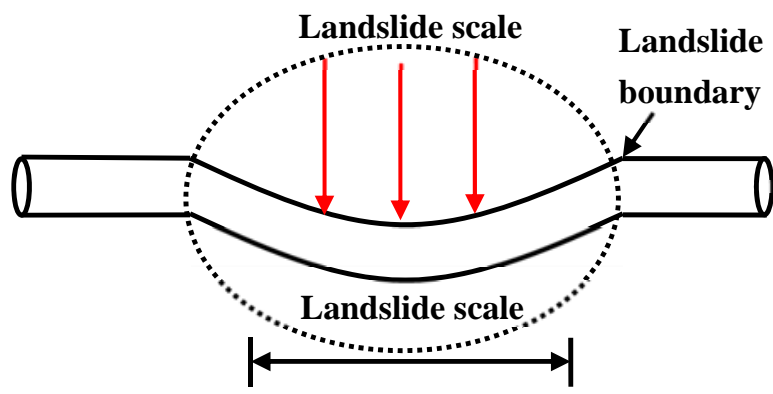

Fig. (1). Laterally traversing pipeline.

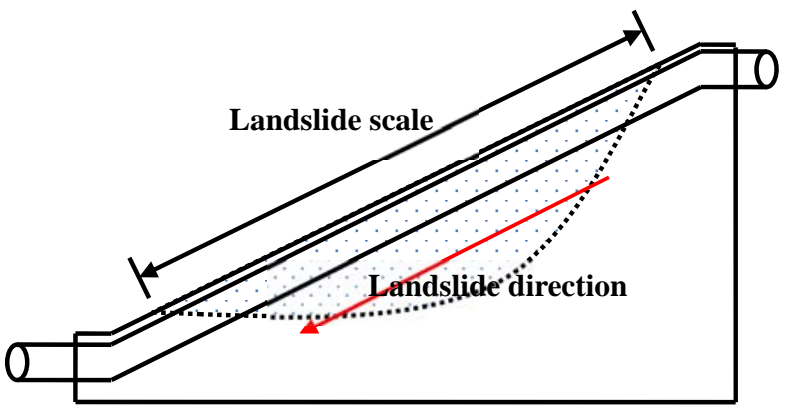

Fig. (2). Longitudinally traversing pipeline.

\subsection{Stress Check Basis}

Stress checks in gas pipelines usually follow ASME B31.8 gas transmission and distribution pipeline system guidelines set by the American Society of Mechanical Engineers (ASME) [14]. Both the laterally traversing and longitudinally traversing pipelines are buried pipelines, so the stress of the pipeline should not be greater than 0.9 pipeline minimum yield strength in operating conditions, which is:

$\sigma \leq 0.9 \sigma_{\mathrm{s}}$

where $\sigma$ is the stress in all kinds of operating conditions, and $\sigma_{\mathrm{s}}$ is the minimum yield strength of the pipeline.

As for an accidental load on the pipeline, the stress should not be greater than the pipeline minimum yield strength, which is:

$\sigma \leq \sigma_{\mathrm{s}}$

where $\sigma$ is the stress in all kinds of operating conditions, and $\sigma_{\mathrm{s}}$ is the minimum yield strength of the pipeline.

\section{RESULTS AND DISCUSSION}

\subsection{Model Overview}

The pipeline crossed a slide mass in the $\mathrm{H}$ section using X80 steel, with an environment temperature of $10^{\circ} \mathrm{C}$. The pipe size was $\mathrm{D} 965 \times 15.9$, with a delivery pressure of $10 \mathrm{MPa}$, and delivery temperature of $40^{\circ} \mathrm{C}$. The model pipeline was laid underground. Regional level was level one, and the design factor was 0.72 . The factors of the pipeline, soil, and working conditions are shown in Tables 1-3.

Note: $W=$ gravity load; $P=$ pressure load; $T=$ temperature load; $U=$ uniformly distributed sliding load.

\subsection{Lateral Traversing}

The total length of the laterally traversing pipeline model slide mass was approximately $800 \mathrm{~m}$, in which the landslide segment was a 16-m straight portion (Node 90-130), symmetrically placed. The landslide surface was approximately $16 \mathrm{~m}$ long, with a slope angle of $15.67^{\circ}$, and a landslide thrust of $4500 \mathrm{~N} / \mathrm{m}$. The pipeline load laterally and

Table 1. Pipe parameters.

\begin{tabular}{|c|c|c|c|c|c|c|c|c|c|}
\hline Material & $\begin{array}{c}\text { Diameter } \\
(\mathbf{m m})\end{array}$ & $\begin{array}{c}\text { Wall } \\
\text { Thickness } \\
(\mathbf{m m})\end{array}$ & $\begin{array}{c}\text { Corrosion } \\
\text { Allowance } \\
(\mathbf{m m})\end{array}$ & $\begin{array}{c}\text { Ground } \\
\text { Allowable } \\
\text { Value } \\
(\mathbf{m m})\end{array}$ & $\begin{array}{c}\text { Density of } \\
\text { Natural } \\
\text { Gas } \\
\left(\mathbf{k g} \cdot \mathbf{m}^{-3}\right)\end{array}$ & $\begin{array}{c}\text { Mounting } \\
\text { Temperatu } \\
\text { re }\left({ }^{\circ} \mathbf{C}\right)\end{array}$ & $\begin{array}{c}\text { Delivery } \\
\text { Temperatu } \\
\text { re }\left({ }^{\circ} \mathbf{C}\right)\end{array}$ & $\begin{array}{c}\text { Delivery } \\
\text { Temperatu } \\
\text { re }(\mathbf{M P a})\end{array}$ & $\begin{array}{c}\text { Minimum } \\
\text { Yield } \\
\text { Strength } \\
(\mathbf{M P a})\end{array}$ \\
\hline \hline $\mathrm{X} 80$ & 965 & 15.9 & 1 & 1.9875 & 95 & 10 & 40 & 10 & 551 \\
\hline
\end{tabular}

Table 2. Soil parameters.

\begin{tabular}{|c|c|c|c|c|c|c|c|}
\hline $\begin{array}{c}\text { Friction } \\
\text { Factor }\end{array}$ & $\begin{array}{c}\text { Density } \\
\left(\mathbf{k g} \cdot \mathbf{m}^{-3}\right)\end{array}$ & $\begin{array}{c}\text { Temperature } \\
\text { Variation }\left({ }^{\circ} \mathbf{C}\right)\end{array}$ & $\begin{array}{c}\text { Internal } \\
\text { Friction Angle } \\
\text { of Soil }\left({ }^{\circ}\right)\end{array}$ & $\begin{array}{c}\text { Soil } \\
\text { Compaction } \\
\text { Multiplier }\end{array}$ & $\begin{array}{c}\text { Buried } \\
\text { Depth (m) }\end{array}$ & $\begin{array}{c}\text { Thermal } \\
\text { Expansion } \\
\left(\mathbf{L} / \mathbf{L} /{ }^{\circ} \mathbf{C}\right)\end{array}$ & $\begin{array}{c}\text { Yield } \\
\text { Displacement } \\
\text { Factor }\left(\mathbf{L} / \mathbf{L} /{ }^{\circ} \mathbf{C}\right)\end{array}$ \\
\hline \hline 0.6 & 1800 & 30 & 35 & 5 & 1.8 & 11.214 & 0.015 \\
\hline
\end{tabular}


longitudinally caused by the landslide thrust can be calculated as:

$\mathrm{UY}=Q \times(-\sin \alpha)=4500 \times(-\sin 15.67)=-1215.43 \mathrm{~N} / \mathrm{m}$

$\mathrm{UZ}=Q \times(-\cos \alpha)=4500 \times \cos 15.67=4332.75 \mathrm{~N} / \mathrm{m}$,

respectively.

An illustration of the pipeline is shown in Fig. (3).

Stress analyses of pipelines is not to simply check for stresses. The stress of pipelines under displacement loads, such as landslides and swamps, are generally required to be calculated. When CAESAR II is used for stress analysis in landslide areas, the results detail the effects of the stress displacement. At the same time, the software provides the locations where the pipeline undergoes great displacements and engineering measures can be proposed to counteract the effects of the stress.

In the summarization of the analysis results, the stress value and the stress ratio are usually given. In order to understand the check results in a more straightforward way, the stress ratio is used for assessment. The stress ratio is the ratio of the stress value at a node to the allowed value of stress (the allowed value of stress is the product of the minimum yield strength of a pipe and a safety factor, namely, the check value of stress).

Figs. (4-7) show the stress and displacement distribution of a pipeline on a laterally traversing slide mass. Conclusions can be drawn as follows:

(1) Fig. (4) is the distribution of the stress rate under working conditions. The pipeline stress under Accidental Landslide Load reaches its highest at $66.4 \%$, the Landslide Load has its highest stress rate at $59.70 \%$, and the No Landslide Load brings the lowest stress rate, which is $55.74 \%$ at its highest. It can be concluded that, in laterally traversing conditions, the pipeline load is affected greatly by landslide loads, among which the influence of accidental landslide loads is bigger than that of landslide loads.

(2) In Figs. (5-7), the axial displacement under Landslide Load conditions is less than that of No Landslide Load conditions, while the lateral and longitudinal loads are heavy. That is because the increasing lateral displacement of the parallel pipeline leads to a decrease of the axial

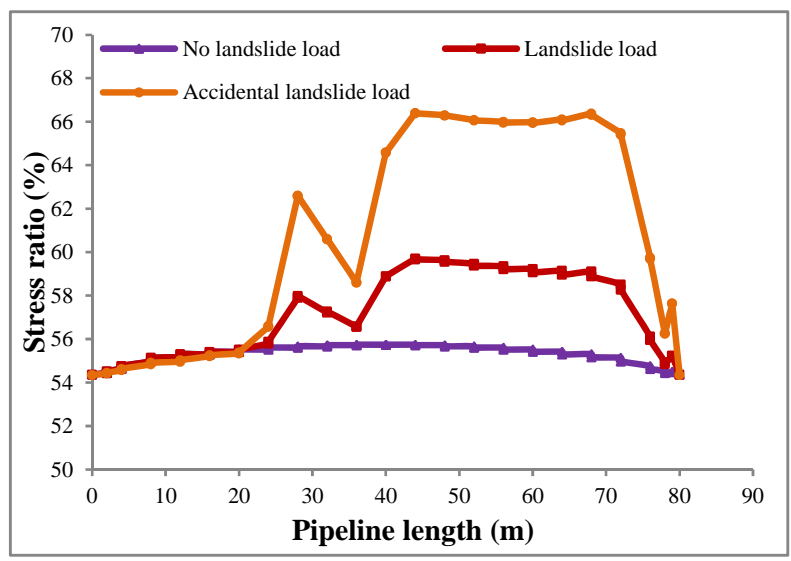

Fig. (4). Distribution of stress rate under working conditions.

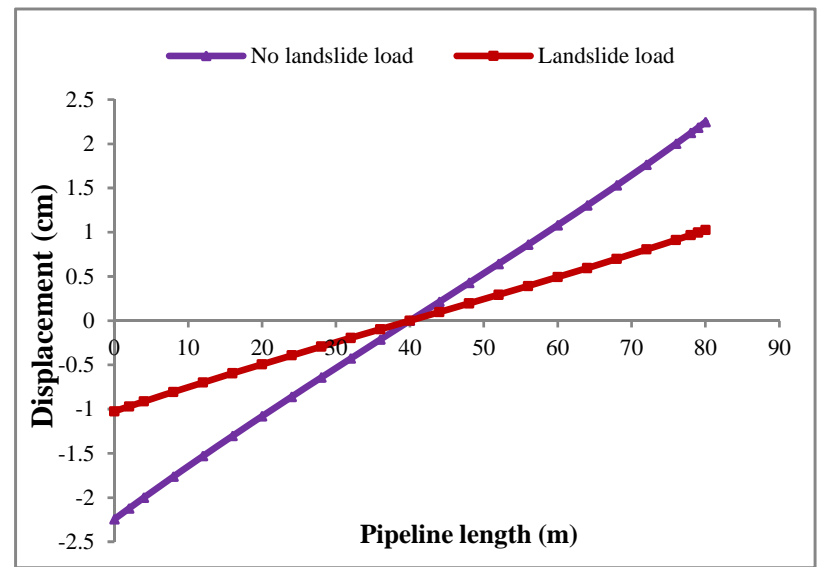

Fig. (5). Axial displacement distribution of pipeline.

displacement.

(3) At the junction of the conventional buried pipeline and the slide mass, the longitudinal and lateral displacements will make a sudden change.

\subsection{Longitudinally Traversing Slide Mass}

The length of the longitudinally traversing pipeline model was $76 \mathrm{~m}$, the gradient length-wise was

Table 3. Load working conditions.

\begin{tabular}{|c|c|}
\hline Working condition & Working condition instructions \\
\hline \hline (1) $[\mathrm{OPE}] \mathrm{W}+\mathrm{P} 1+\mathrm{T} 1$ & Working condition under no sliding load \\
\hline (2) $[\mathrm{OPE}] \mathrm{W}+\mathrm{P} 1+\mathrm{T} 1+\mathrm{U} 1$ & Working condition under sliding load \\
\hline (3) $[\mathrm{OCC}] \mathrm{W}+\mathrm{P} 1+\mathrm{U} 1$ & Working condition under accidental sliding load \\
\hline
\end{tabular}

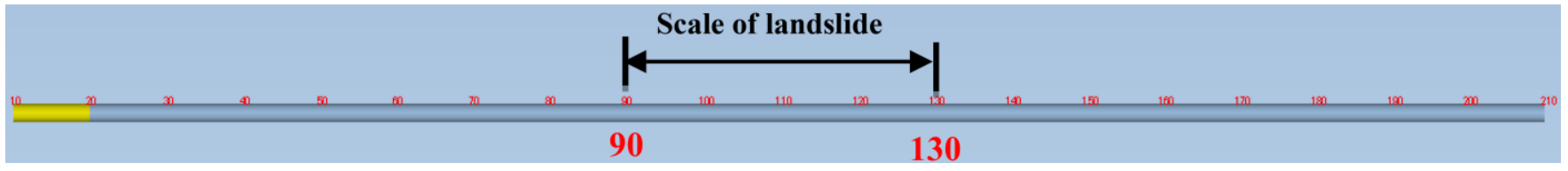

Fig. (3). Sketch of laterally traversing pipeline slide mass. 


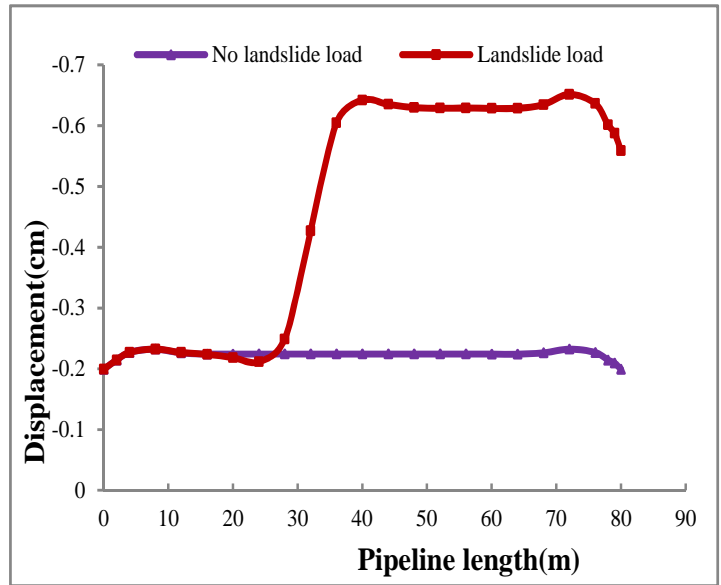

Fig. (6). Longitudinal displacement distribution of pipeline.

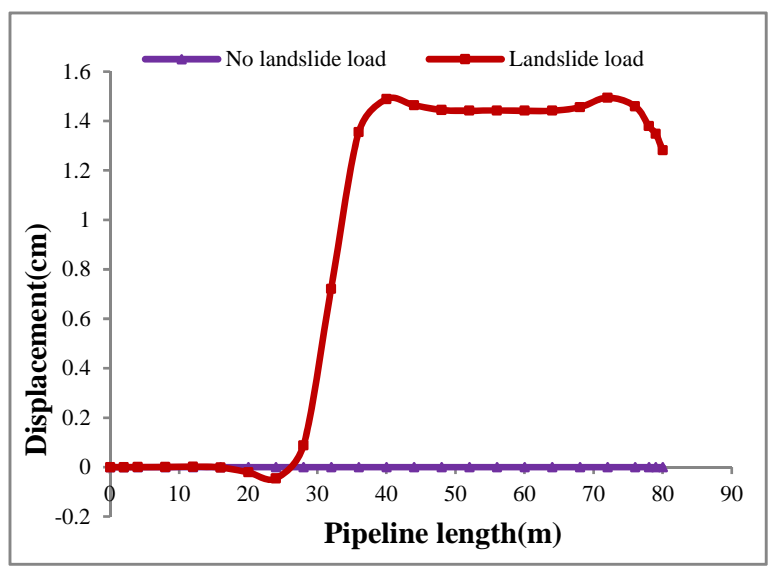

Fig. (7). Lateral displacement distribution of pipeline.

approximately $15^{\circ}$, the length of the landslide surface was $16 \mathrm{~m}$ (Node 90-130), the landslide surface angle was $17.12^{\circ}$, and the landslide thrust $Q$ was $4500 \mathrm{~N} / \mathrm{m}$. The evenlydistributed loads on the pipeline laterally and longitudinally caused by the landslide thrust can be calculated, respectively, as follows:

$\mathrm{UX}=Q \times(-\cos \alpha)=4500 \times(-\cos 17.12)=-4300.6 \mathrm{~N} / \mathrm{m}$

$\mathrm{UY}=Q \times(-\sin \alpha)=4500 \times(-\sin 17.12)=-1324.68 \mathrm{~N} / \mathrm{m}$

The sketch of the pipeline is illustrated in Fig. (8).

Figs. (9-11) show the stress and displacement distribution of the pipeline when longitudinally traversing a slide mass, and conclusions can be drawn as follows:

(1) In Fig. (9), the pipeline stress under Accidental Landslide Load reaches its highest at $61.19 \%$, the Landslide Load's

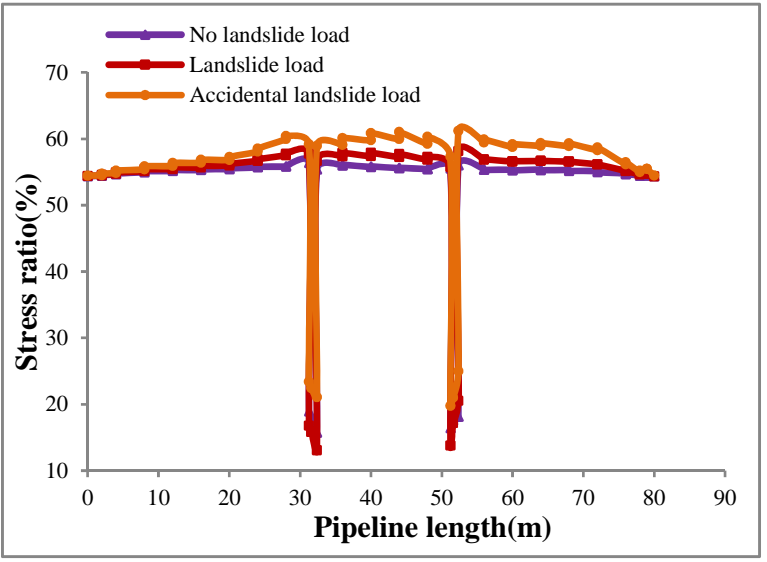

Fig. (9). Distribution of stress rate under working conditions.

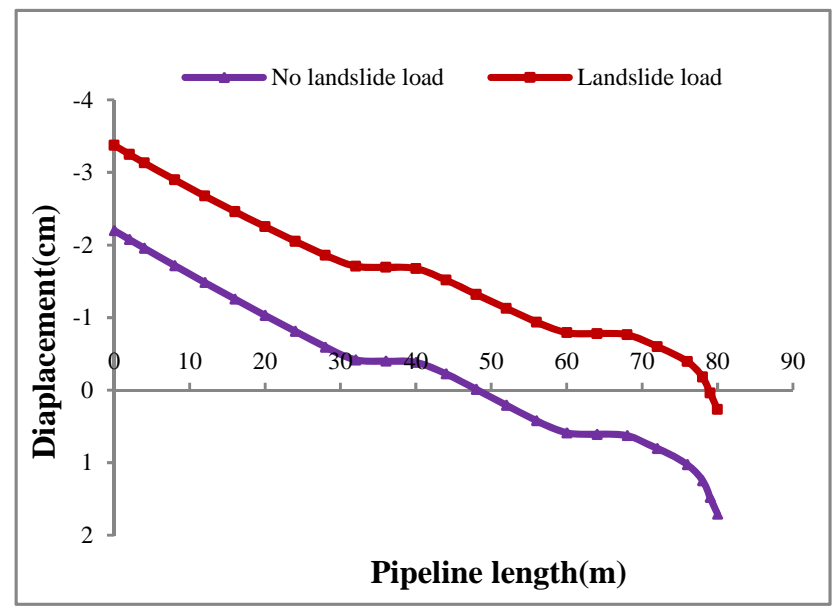

Fig. (10). Axial displacement distribution of pipeline.

highest stress rate is $58.16 \%$, and the No Landslide Load creates the lowest stress rate, which is $56.36 \%$ at the highest, all of which are close. This illustrates that when a pipeline traverses a slide mass longitudinally, the influence of pipeline stress caused by the landslide load is much smaller.

(2) In Fig. (9), it is obvious that the pipeline stress suddenly changes at the junction of the conventional buriedpipeline and the slide location.

(3) In Figs. (10 and 11) it can be seen that the pipeline stress under Landslide Load conditions is greater than that of No Landslide conditions, and the length-wise displacement changes suddenly at the junction of the conventional buried-pipeline and the slide location. However, the buckling trend to happen if the stress is over-large.

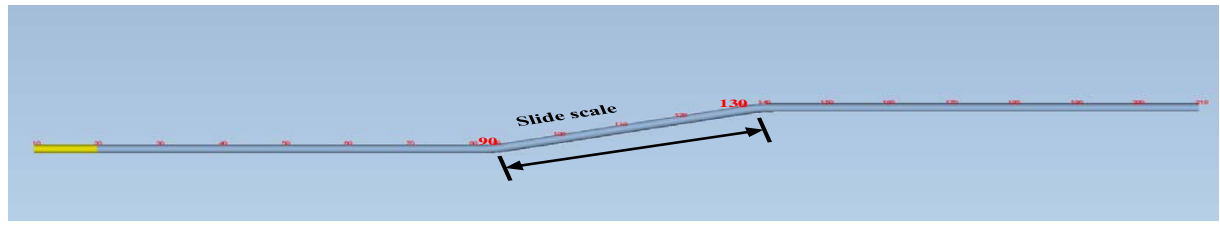

Fig. (8). Sketch of pipeline traversing slide mass longitudinally. 


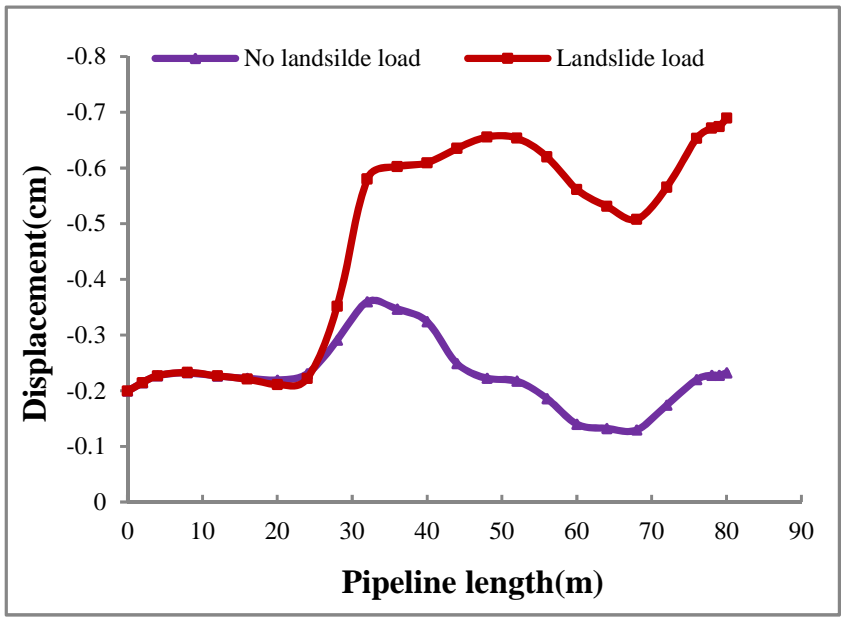

Fig. (11). Longitudinal displacement distribution of pipeline.

\section{CONCLUSION}

Through the study, it can be concluded that:

(1) According to the stress analysis of the pipeline laterally and longitudinally traversing the slide mass, the junction of the conventional buried pipeline and the slide mass is the section that sees the most stress.

(2) From the pipeline stress and the displacement distribution, the stress under an accidental load is the biggest in both laterally and longitudinally traversing situations. Therefore, it is suggested that when analyzing the stress in the engineering phase, the pipeline stress under accidental landslide loads should be carefully investigated in order to avoid costly repairs.

(3) When a gas pipeline laterally traverses a slide mass, the pipeline stress is greatly influenced, but the impact on the pipeline is smaller when traversing longitudinally. As a result, priority should be given to designing longitudinally traversing pipelines whenever possible.

For a landslide-area-crossing gas pipeline, displacement and scale should be monitored, and a suspended pipeline can receive added protection from a retaining wall.

\section{CONFLICT OF INTEREST}

The authors declare that there is no conflict of interest regarding the publication of this article.

\section{ACKNOWLEDGMENTS}

This research is supported by Science and Technology Innovation Foundation of CNPC (2012D-5006-0602). And special acknowledgement should be given to the ProjectResearch on technology of improving and optimizing the cold energy utilization efficiency of LNG receiving station from Southwest Petroleum University.

\section{REFERENCES}

[1] K. Huang, S. J. Wu, L. Q. Chen, H. F. Lu, Y. T. Lv, and J. L. Wu, "Stress analysis of oil and gas pipeline parallel laying when traversing tunnels," J. Chem. Pharma. Res., vol. 6, pp. 1248-1254, June 2014.

[2] H. Y. Jing, J. B. Hao, K. Z. Chen, J. P. Liu, B. Han, and Z. Z. Wu, "Monitoring and early-warning technology and application in pipeline landslides," Chin. J. Geolog. Hazard Cont., vol. 20, pp. 124-129, December 2009

[3] X. N. Wu, H. F. Lu, K. Huang, X. Y. Tang, S. J. Wu, G. Y. Shen, and H. P. Fu, "Stress analysis of gas pipelines at seismic belts based on the spectrum analysis," Natural Gas Ind., vol. 34, pp. 152-157, May 2014.

[4] J. Shuai, X. L. Wang, and S. Z. Zuo, "Breakage action and defend measures to pipeline under geological disaster," Welded Pipe Tube, vol. 31, pp. 9-15, September 2008.

[5] K. Huang, H. F. Lu, K. R. Shen, H. W. Shu, and Y. J. Wang, "Study on buttresses distance of gas pipelines in the deviated well based on stress analysis method," Adv. J. Food Sci. Tech., vol. 5, pp. 12491254, September 2013.

[6] K. Huang, S. J. Wu, H. F. Lu, Y. Xian, and Q. W. Su, "Stress analysis of the pipeline laid along the slope," Natural Gas Oil, vol. 30, pp. 1-4, August 2012.

[7] X. G. Wu, Q. Zhou, and H. F. Lu, "Stress analysis of CAESAR IIbased buried oil pipelines," Pipeline Tech. Equip., vol 21, pp. 1618, March 2014.

[8] X. N. Wu, H. W. Shu, L. F. Zan, X. Jiang, D. H. Hu, and Z. Xie, "Stress analysis of a gas pipeline through shield tunnels under pressure test conditions," Natural Gas Ind., vol. 33, pp. 73-77, March 2013.

[9] X. N. Wu, Y. Xian, K. Huang, M. L. Hu, and B. J. Shang, "The stress analysis of tunnel gas pipeline under operating situation," Oil Gas Storage Transport., vol. 31, pp. 927-930, February 2012.

[10] X. N. Wu, Y. Jiang, H. F. Lu, S. J. Wu, and X. X. Chen, "Stress analysis of shallow sea gas pipelines," Res. J. Appl. Sci., Eng. Tech., vol. 7, pp. 157-160, January 2014

[11] X. N. Wu, H. F. Lu, S. J. Wu, H. Kun, X. Chen, F. X. Kang, and Z. L. Liu, "Analysis of suspended pipeline stress sensitivity," Appl. Mech. Mat., vol. 501, pp. 2331-2334, July 2014.

[12] J. B. Hao, J. P. Liu, H. Y. Jing, H. Y. Zhang, F. J. Shen, H. L. Tong, and L. M. Liu, "A calculation of landslide thrust force to transverse pipelines," Acta Petrolei Sinica, vol. 33, pp. 1093-1097, November 2012.

[13] Q. Xie, W. Wang, J. H. Zhang, and P. Xiang, "Longitudinal stress analysis of pipeline buried in two different forms of landslide," Chin. J. Underground Space Eng., vol. 8, pp. 505-510, June 2012.

[14] ASME. ASME B31.8 Gas transmission and distribution piping systems. New York: American Society of Mechanical Engineers Press, 2010. 